\title{
Competition as instituted economic process
}

\author{
Mark Harvey
}

\section{Introduction}

A challenge to the new economic sociology is that central economic processes should become the focus of theoretical and empirical sociological analysis. This chapter makes some steps towards analysing competition in that light, partly because competition is often assumed to be the market force of all market forces. The central argument made is both that competition processes are co-instituted with markets (including end markets), and that market processes are in turn co-instituted with industrial divisions of labour. Thus, it is suggested that an excessive burden of explanatory expectation is placed on competitive processes within markets, as the dynamic of capitalist economies. Indeed, I argue here that many conceptions of competition suffer from this 'tilt towards the market' as the sole or primary dynamic force behind economic growth, to the exclusion or at least sidelining of complementary but at least equally significant dynamics within the realm of production, such as capital accumulation. After all, to put it at its weakest, competition may stimulate but cannot deliver growth, and in some models of competition, the outcome is merely the efficient allocation of existing resources through transparent price setting, a static equilibrium model.

The chapter begins with an examination of some of the few empirically based studies of competition, suggesting that they often are developed for overtly normative or prescriptive purposes. It then returns to analyse some of the early Weberian conceptions of competition, upon which to build an economic sociology of competitive processes. After contrasting the seminal concept of 'instituted economic process' with the other and more widely adopted Polanyan legacy of 'embeddedness', the chapter explores competition as an instituted economic process in five dimensions: the co-institution of competitive processes and markets; relations of power and mutual dependence between classes of economic agent; the formation of units of competition; the formation of scales of competition; and the development of formal and informal norms of competition. The chapter then provides an exemplification of this analytical framework through a schematic analysis of changing forms of competition in the historical development 
of UK food supermarkets. The conclusion drawn from this analysis is that competitive processes are a result of processes of transformation wider than intra-market dynamics.

\section{Empirico-normative views of competition}

Leaving aside neo-classical views of 'perfect competition', this much acclaimed market force has attracted surprisingly few empirical 'competition studies' to complement those in the field of innovation. There is a wide range of conceptions of what constitutes competition: static efficiency of resource allocation: dynamic efficiency of innovation and adaptation; and Schumpeterian creative destruction. But many of these conceptions are what might be called 'empirico-normative', stating as much what ought to be as what is. A classic instance of this is the work of Porter, which comprises the more overtly prescriptive (1985) with empirico-normative analysis (1998a, b). 'Competition is dynamic and rests on innovation and the search for strategic difference' (Porter, 1998a, p. 209) is a proposition that rolls together statements about what competition is, empirically and optimally, into what amounts to a definition. Clusters of interconnected firms are seen to provide optimal competitive conditions for strategic differentiation, with the Porter diamond being used as a strategic tool for achieving the best combination of its four facets: factor inputs, supply chain networks, demand conditions, and regulatory frameworks and infrastructure. In this way, clusters are seen as being capable of going beyond static efficiency competition, beyond cost-reduction competition, and onwards and upwards to optimal forms of competition based on strategic differentiation. ${ }^{1}$ Low barriers to entry into clusters, levels of 'social capital' ensuring free flows of information, absence of formal contractual requirements resulting from a level of common purpose, combined with an exactly right dose of rivalry in the cluster, ${ }^{2}$ are thus empirical characteristics, ones given the normative seal of approval. Empirical cases, such as the birth of the Medtronics' pacemaker cluster in Minneapolis, are thus woven into the narrative as 'exemplary' events as much as evidential demonstration.

Cartels are bad (they 'undermine economic value') while clusters are good ('open', 'facilitating', 1998a, p. 227). The best kinds of clusters are to be found mostly in the USA, where the greatest number provide the greatest synergies arising from overlapping clusters, whereas in developing countries clusters tend to be too centralised around a few dominant players, are often state supported, and are 'hub-and-spoke networks' (1998a, p. 231). Japan is castigated for following such a model, exacerbated by a metropol-centric and overdirected bias. Given this fusion of the empirical and the normative '[c]luster theory emphasises not market share but dynamic improvement. This results in a positive sum underlying view of competition, in which productivity improvements and trade expand the market' (1998a, p. 249). There exists empirically an optimal kind of competition and its effects are unreservedly benign. 
Two examples of theorisation of competition which are clearly empirically based but nonetheless attached to an advocacy of particular forms of competition can be found in the work of Best (1990), on the one hand, and in a network of researchers clustered around the Applied Economics Department and the ESRC Centre for Business Research at Cambridge University, on the other. In an historical analysis of different forms of competition, Best argues that changing forms of competition are the outcome of complex interactions between industrial divisions and productive organisation, on the one hand, and formal competition regulatory systems, on the other. Thus, in the USA the multi-divisional Chandlerian corporation involved a form of competition in which Big Business mass production responded to conditions of oversupply by further increasing supply to achieve greater market share in shrinking market conditions, and by market expansion, 'democratic consumption', in growth conditions. The regulatory framework provided by corporation law and Sherman's Anti-Trust Law had the unintended consequence of accelerating acquisition and consolidation by criminalising inter-firm co-operation.

By contrast the 'New Competition', which involves strategic differentiation, organisational superiority and continuous innovation in a shifting competitive environment, emerges when inter-firm relationships across the production chain are facilitated by consultative co-ordination. A balance is struck between sectoral inter-firm co-operation on prices to enable competition for innovation potential. And there is an enabling and supportive policy framework and infrastructure subverting the dichotomy between market and hierarchy which sustains a 'balance between co-operation and competition' (Best, 1990, p. 267). The particular form of the keiretsu in Japan as they evolved during the 1970s was thus once more an industrial and productive organisation in interaction with a competition regulatory environment. Best argues strongly that this development was an unintended consequence of an institutional countervailance between MITI and the Free Trade Commission, preventing either the dominance of centralised and directive planning or the imposition of US-style competition law.

United States industrial regulatory policy had presumed the idea of perfect markets and defined inter-firm co-operation as collusion against the public interest. Japanese industrial policy, in contrast, has been based on the presupposition that a mix of inter-firm competition and co-operation can promote international competitiveness. (Best, 1990, p. 201)

The 'Third Italy' provides another example of a complex interaction between trade associations, consortia and municipally sustained tax and 'social capital' infrastructure facilitating collective Schumpeterian competition for strategic sectoral advantage, also balancing competition and co-operation. It is clear, from this account, that for Best 'the purpose of strategic industrial policy is to promote Schumpeterian competition and (collective) entrepreneurial firms', and that ' $[\mathrm{t}]$ his means, in part, shaping competition and affecting the form that competition takes in order to enhance economic performance' 
(1990, pp. 265-6). The empirical analysis is one in which particular historical forms of industrial division and organisation generate distinctive forms of competition (focusing on productivity cost reduction, on market share, or on strategic differentiation, innovation and comparative organisational advantage). These forms of industrial organisation and competition are then sustained by and, in their turn influence formal institutional competition regulation. In Best's work there is a strong sense, too, that the New Competition is both historically and normatively superior to an antecedent and moribund Big Business corporation form of competition. ${ }^{3}$

The 'Cambridge network' has likewise produced a number of comparative studies of competitive and co-operative behaviour, combining legal, economic, sociological and management perspectives. Lane (1997) demonstrated how different technical and quality norms operating in markets in Germany and Britain effectively provide a distinctive basis for collaboration and competition in the former by establishing industry-wide common standards. In Britain, in contrast, in the absence of specified quality and technical standards, quality and cost can more easily become opposing objectives of competition. Likewise, contractual law, a propensity to litigate, and the fostering of trust have been analysed as being central to different forms of inter-firm relations which fundamentally affect the nature and focus of competitive forces in Britain, Germany and Italy. Institutional and legal infrastructures thus form part of the essential basis for co-operative productive systems which enhance their innovation capacity and hence their competitiveness (Deakin and Wilkinson, 1995; Arighetti et al., 1997; Deakin, Lane and Wilkinson, 1997). Complementary to Best's analysis of the role of competition regulation, these authors also demonstrate how regulation policy in the USA followed economic fashion, first the Chicago School, then game-theoretical and principalagent theories, to shape a particular kind of competition environment through key legal cases. They contrast this with the regulatory environments in the UK and at the European Commission levels (Deakin, Goodwin and Hughes, 1997), and suggest ways in which these differently affect competitive behaviour. ${ }^{4}$ This body of work, which places a central emphasis on formal and contractual institutions and the way they shape competitive and interfirm relations, also shares a common normative standpoint, both by providing an effective critique of regulatory models assuming atomistic competition, and in promoting a view that 'co-operation between firms is a necessary productive feature of productive innovation and competitive success' (Deakin et al., 1997, p. 339). The comparative study, therefore, provides an important lever of judgement for critiquing 'the broad orientation of systems of competition law which continue to privilege models of industry based on atomistic competition' (p. 362).

Drawing this introductory discussion to a close, it is clear that in this field of empirical analysis, some important if partial analyses have been made. These far surpass the prescriptive and normatively motivated account of competition by Porter, and even more so the formal models of 'perfect competition'. Best 
gives the most comprehensive theoretical basis for an analysis, embracing the historical development of industrial organisation, in parallel with formal institutional regulatory regimes. But that analysis leads towards a more normative account of the virtues of Schumpeterian collective entrepreneurship of the New Competition. The 'Cambridge network' provides significant additional perspectives, emphasising especially formal institutional conditions for co-operatively based competition. But, lacking Best's perspective on industrial organisation and, especially, consideration of power relations in vertically organised supply chains, the analysis of co-operation also tends to be normatively laden.

\section{Towards an instituted economic process approach}

If one looks hard enough, it is generally possible to find antecedents for most ideas, and the early formulations of a synthetic discipline of economic sociology do provide some initial pointers to an instituted economic process view of competition. 'A market may be said to exist wherever there is competition, even if only unilateral, for opportunities of exchange among a plurality of potential parties' (Weber 1968, p. 635).

Swedberg $(1994,1998)$ has argued that Weber enlarges a conception of markets beyond their status as simple vehicles for exchange by distinctively pairing exchange with competition as a prerequisite for the existence of markets, but he still leaves much to be done analytically. In particular, competition is here defined fairly restrictively in terms of a struggle over opportunities for exchange. That struggle is one into which power directly enters. Indeed, for Weber economic competition is a form of 'peaceful conflict', whereby attempts are made to 'gain control over opportunities and advantages which are also desired by others' and which take place 'in exchange relationships, bound ... by the order governing the market' (Weber, 1968, p. 38). Although not clearly stated, Weber clearly intends that competition here involves winners and losers, and thereby a process of 'social selection' (1968, pp. 38-40). In this view of competition as a pacific power struggle, however, it appears that the power exercised within the market and through the exchange process is not explicable by the market or exchange relations alone. To found a notion of relative powers, it is necessary to include the sphere of production and the differential capacities to create and own wealth. ${ }^{5}$ Moreover, Weber's action-oriented approach is undoubtedly an obstacle to an analysis of the power relations that arise from industrial divisions, such as those between capital and labour, between primary and secondary producers, or between retailers and manufacturers, retailers and consumers. The 'elemental' description of a market as a plurality of buyers confronting a plurality of sellers (Weber, 1968, p. 635; Swedberg, 1998, pp. 42-3) already makes important assumptions about their separation into two classes of economic agent which is difficult to account for in terms of actor-oriented agency. 
Nonetheless, Weber's ideas of economic competition as 'pacified' struggle and of exchange as one that obeys rules of calculation embodied in market organisation anticipate some notion of normalised or instituted competitive process. Moreover, as Swedberg has commented, Weber hesitated in Economy and Society to take this view of economic competition in exchange to develop a theory of price, restrained by fear of transgression into the field of economics and marginal utility theory. But he privately acknowledged that the logic of his position would be to view real price formation as an empirical process resulting from the economic struggles between actors (Swedberg, 1998, p. 44). This, were it to be developed further, provides intimations of an instituted economic process (IEP) account of price and price formation, through 'economically normalised' competitive struggle. What this significantly shares with an IEP approach is that core economic processes, such as price and competition, as well as markets, are seen as 'normalised' ipso facto for being economic, and that the 'rationality' of markets and market agents is itself a consequence of normalisation.

The notion of economic processes as instituted was first explicitly formulated by Karl Polanyi, and in order to weigh its full significance it is first necessary to disentangle it from the concept of embeddedness for which Polanyi is much better known, as well as from its pair dis-embeddedness which, equally, has found less favour. It should be emphasised that this is an attempt to develop the notion of IEP from the rather confused and, tangled usage within Polanyi's own work, on the one hand, and on the other, to suggest that Polanyi had in embryo a much more radical agenda than the subsequent appropriation of embeddedness, notably by Granovetter (1985, 1992 and with McGuire, 1998), has given it. The concept of embeddedness carries with it the idea that economic relations are moulded and shaped by the social relations and contexts within which those relations occur (Polanyi, 1944, pp. 46, $49 ; 1957$, p. 250). ${ }^{6}$ Thus, in the terms of the above discussion of legal and contractual institutions, the concept might be used to say that transactions are 'embedded' in such a societal framework. Granovetter, however, appropriated the concept for the purpose of developing a more actor-oriented approach, with embeddedness referring to 'dense and stable networks of relations, shared understandings, and political coalitions' (Granovetter, 1985 , p. 501). And he argued that trust and co-operative relations developed through 'concrete personal relations and the obligations inherent in them ... quite apart from institutional arrangements' (1985, p. 495). In more recent work, this type of analysis is taken to an extreme in which, at a more macro level than in his previous work, small-scale interpersonal networks, even conspiracy between a handful of people, were seen as constructing the overall industrial structure, including the competitive relations, of the electricity supply industry in the USA. ${ }^{7}$ Moreover, this perspective is applied to industrial organisation more generally, by arguing that

processes and relationships once shaped by individuals became institutionalised in more formal organisations, institutional alliances, standardised practices, and 
industry norms. As in other industries ... such patterns become embedded as norms, unless and until an industry-wide crisis occurs. (Granovetter and McGuire, 1998, p. 168)

Callon (1998) extends this notion in an actor network context, suggesting that the idea of embeddedness is one which means, firstly, that all levels of analysis are reduced to 'the network of interactions' in which individuals are involved, ${ }^{8}$ and, secondly, that as such networks bind economic, social, political, cultural, technological and material aspects together, there is in principle no distinct sphere of the economic that can be analysed as such. Indeed, in this conception of embeddedness, Callon argues that we are now increasingly living in 'hot' situations where it becomes difficult to 'frame' the economic into a distinct sphere of economic calculation, and there is a continuous 'overflowing' into networks too fluid for economic calculation.' Only in 'cold' situations, when markets are discrete, framed, and immune from excessive externalities, are Coasian or other economically rational calculations possible. Thus, the idea of embeddedness here invoked suggests the continuous and overwhelmingly invasive presence of incalculable externalities in market interactions.

In tracing this lineage of the concept of embeddedness, its latent potential for sociologising the economy out of existence, and of dissolving institutions of price, capital, competition, industrial division of labour, supply, demand, market, etc., into emergent networks of interpersonal relations becomes manifest. This seems quite remote from Polanyi's original intention and usage. Indeed, analysing the development of the 'self-regulating market' in The Great Transformation, Polanyi suggested very forcefully that during the industrial revolution all factors became commodities (including, notably, land, labour and money). That was a key historical moment when economic institutions became dis-embedded or even entailed a reverse embedding of society into the economy. It is that formulation which gives such a different reading to the concept of embeddedness:

Instead of economy being embedded in social relations, social relations are embedded in the economic system ... For once the economic system is organised in separate institutions, based on specific motives and conferring special status, society must be shaped in such a manner as to allow that system to function according to its own laws ... A market economy can function only in a market society. (Polanyi, 1944, p. 57)

The commodification of labour, in particular its separation from preceding modes of subsistence living, and the development of urbanisation, meant that many more social interactions were mediated by money exchanges and price, and as such became economically instituted. That was the intent of the more general formulations Polanyi later gave (1957, p. 250) where he stated:

The instituting of the economic process vests that process with unity and stability; it produces a structure with a definite function in society; it shifts the place of the process in society, thus adding significance to its history; it centres interest on 
values, motives and policy ... The study of the shifting place occupied by the economy in society is therefore no other than the study of the manner in which the economic process is instituted at different times and places.

When speaking of motives, values and policy as also instituted, he adopts formulae akin to a notion of habitus where 'no individual economic motives need come into play' (Polanyi, 1944, p. 49), because social organisation 'runs in its ruts', and the motive for gain, in becoming generalised in tandem with a commodified economy, is one of those ruts (Polanyi, 1944, pp. 41-2).

The central consequences that can be drawn out of this approach are threefold. First, given that economic process is an instituted process, open to deand re-institution, it is socially, comparatively and historically variable. That applies to capital, labour, price mechanisms, markets - as well as to economic motives. It fundamentally underpins a notion of varieties of capitalism. Second, rather than talking of instituted economic processes and their context as socially 'embedding', the specificity of economic instituted processes can be seen to find their 'place' in different articulations with legal, political and civic institutions. So there is no question of the economic being dissolved in the social, or vice versa, as with an over-sociologised view of embeddedness. Rather there is mutual conditioning between, for example, competition law and industrial organisation (as with Best). Third, and likewise, an IEP approach opens up the possibility of running through from micro to macro, from the motive for gain to the Gold Standard, and the articulation between different scales of instituted process. Thus, for Polanyi, both the motive for gain and the Gold Standard are prime examples of the instituted economic process, the former very likely being articulated with all kinds of networks of interdependences at the micro-social level (in the manner of Granovetter); the latter being a transnational, trans-societal, instituted economic process, relatively dis-embedded from such micro-social networks.

\section{Competition as instituted economic process}

Developing an IEP approach in relation to competition will involve looking at a number of different dimensions, under the basic assumption that competition, far from being a universal or natural law of the market, is instituted differently in different historical and comparative circumstances. The focus becomes the study of competition in its varied modes of institution, and competition, being multi-dimensional, needs to be analysed as a complex phenomenon. In many ways, this section is programmatic, to be followed by the next, where the rise of UK supermarkets will be used as an illustrative example of a multi-dimensional reconfiguration of competition.

Markets and forms of competition are mutually instituted

The starting point for an understanding of competition as an instituted economic process is that it is manifest in market exchanges, as indeed we saw 
Weber suggest. So even empirical examples of 'perfect competition' à la Samuelson can be discovered, as Garcia (1986) has demonstrated for a strawberry market, near Paris, in Sologne. She showed that in this market there was relative equality between buyers and sellers; unrestricted entry into the market; homogeneity of the product; and transparency or near perfect information. But unlike a view of embeddedness, ${ }^{10}$ this market was the effect of a quite distinct process of institution which involved a number of different preconditions. First, it required the elimination of one form of trading institution (the itinerant merchant-grower) and its replacement by a computerised local auction. Second, the growers' association attracted the assistance of the central and the local state in the funding of the market institutions, such as the central collection hall for display of produce and an electronic terminal and screen system. Third, homogeneity of product was ensured through collective quality regulation and a common grading system, adopted by the growers. And, last but not least, a balance of power with purchasers was achieved as a result of the formation of a growers' association. Buyersupplier equality was, somewhat precariously, facilitated by the particular patterns of land ownership among growers, and relatively small-scale retailers or market traders coming from Paris. In other words, the balance of power, or equality between buyers and sellers, pre-supposed special social and economic characteristics of both sets of agents. In short, the form of competition, so-called 'perfect competition', was instituted - but only under quite special social and historical circumstances.

In a more general way, it can be seen that the formation of the broad categories of labour, product and capital markets, each with its own distinctive competitive processes, ${ }^{11}$ is itself the outcome of instituted economic process. The institutions of a stockmarket, for example, involve quite distinct, and historically changing, processes of competition, as can be seen from various developments and possibilities of European or cross-Atlantic merger, alongside distinctive rules for trading, and formal regulation.

Comparing distinct European labour markets, it is clear that different quality and pricing institutions for labour, and different frameworks for regulating long-term, short-term, temporary and part time contracts, fundamentally condition the forms of competition within labour markets (Harvey, 2000; Harvey et al., forthcoming). A conclusion from these works is that the labour contract, the commodity purchased and hence the exchange between capital and labour are radically differently instituted in differing countries. Moreover, such differences have led to major political debates about the competitiveness of 'high social cost' and 'low social cost' labour. However, given the radical incommensurability between what is being purchased in two disparate labour markets; given the 'indirect' competition via product markets; and given exchange-rate fluctuations, it is clear that there an absence of 'normalised' competition at this level. There are no overarching instituted measures in the absence of a common currency. So, from an IEP perspective, the indirect competition between diverse labour markets via 
product markets and institutional forms of fluctuating exchange rates and monetary institutions exemplifies the institutedness of competition. I return to this point in considering different instituted scales of competition.

\section{Asymmetric power and mutual dependence}

Competition generally takes place within the same class of economic agent, but not between classes of economic agent, and the formation of such classes is itself a result of instituted economic process. Thus, to continue with labour markets, the focus of competition is among employers (capital) and among employees (labour), across an exchange relationship, as a consequence of the formation of two distinct classes of economic agent performing distinct economic functions. ${ }^{12}$ But competition does not occur between labour and capital. ${ }^{13}$ The exchange relation is characterised by mutual dependence (owners of capital need labour; people are, in varying ways, obliged to sell their labour) and asymmetrical power relations. The kind of power wielded by capital (degree of concentration, domination in the market, etc.) is different from the kind of power wielded by labour (from individual sale through to various forms of countervailing association). In this exchange relation, the nature of competition as affected by concentration or organisation of capital on one side of this power equation affects the opportunities of exchange, just as the nature of competition on the other side of the equation can be affected by forms of association and by labour market institutions of the kind suggested above.

But the more general proposition that competition applies within and not between classes of economic agent is also applicable to exchange relations between retailers and consumers, retailers and manufacturers, manufacturers and primary producers, and so on. Each of these pairs can be seen as classes of economic agent, historically instituted, and performing distinct economic functions. New classes, still in the process of institutionalisation as is the case with the emergence of e-commerce, can fundamentally restructure the configuration of existing exchange relations, thereby instituting new forms of competition. I explain later how the emergence of powerful supermarkets has affected the structure of exchange relations, and hence of forms of competition.

Thus, as with capital and labour, retailers as one class of economic agent can be seen to compete with retailers, but not with farmers or manufacturers or consumers, as other classes of economic agent. Vertical exchange relations along a supply chain are significantly affected by the shifts in asymmetrical power relations, as will be seen. But those power relations must be distinguished from competitive relations. Consequently, in so far as retailers and manufacturers, for example, are mutually dependent and in asymmetrical power relations, it is important to consider that if competition does not occur across classes of economic agent, nor does co-operation in the sense of unconstrained mutual co-operation between similar equals. It becomes important to distinguish co-operation between members of the same class of economic agent (trade associations, employers federations, trades unions, etc.) from 
forms of concertation that occur within exchange relations characterised by mutual dependence and power asymmetry, a form of economic constraint (retailers have to acquire goods from manufacturers, manufacturers have to find a way to market). For co-operation between economic agents of the same class, Richardsonian notions of complementarity of dissimilar capabilities (Richardson, 1972) may be appropriate, and Marshallian districts can be taken as empirical examples (Best, 1990 $;{ }^{14}$ Dei Ottati, 1994).

It should be stressed that there are two aspects to power asymmetry: on the one side, relative balance or position as a consequence of size and levels of concentration within one of two economic classes party to the exchanges, and, on the other, the nature of the power wielded. Thus, as a result of concentration, retailers may control and shape access to market. But this is a very different type of power or capacity from that involved in the productive capacity of manufacturers. In terms of instituted economic process, therefore, one could contrast the power of food retailers in the UK in relation to food manufacturers with the power of motor manufacturers and franchised retail outlets. These two instituted exchange relations affect fundamentally the nature of the competition, the pricing mechanisms - and also the power of consumers in relation to either of those two arrangements.

Referring back to Best's historical analysis of changing forms of competition with changing patterns of industrial organisation, that can now be reformulated in an IEP perspective where the development and differentiation of classes of economic agent, within a given sector of production, affect the nature of competition within those classes, not least because differentiation affects the nature of power asymmetries and mutual dependences between classes of economic agent. To return also to Weber, the way power enters into economic exchanges is centrally through the asymmetry and mutual dependences of trading relations between differently constituted classes of economic agent.

Units of competition and the 'channelling' of competition

If competition is variously instituted by the formation of markets and by the configuration of different classes of economic agent, then a further dimension of the shaping of competition arises from the institution of different units of competition, from individuals to firms, supply chains, or clusters of firms. The formation of different units of competition should be distinguished from the formation of different scales of competition, which are discussed below, the former concerning primarily the competitive entities within a given market, the latter the scale of the markets themselves - local, regional, national or global. So, to emphasise the distinction, transnational corporations can compete with each other, but at various different scales of competition in different markets. ${ }^{15}$ The assumption of much competition regulation is that the firm is the only unit of competition, and the objective of such regulation is to institute norms of competition for firm behaviour, in specified markets. Indeed, in many instituted markets, firms can be the central and dominant units of 
competition, and there are degrees of 'atomism' in this respect, depending on the levels of repeat trading or formal and informal partner relations between firms within different economic classes (Fulconis, 1999).

But, in many contemporary product markets, the competing units are integrated supply chains, networks or clusters, each of which can be orchestrated by the dominant power within it. The locus of power within the supply chain, and the degree of integration of the supply chain, fundamentally affect where the competition is channelled, and, as I argue below, what form the competition takes in terms of cost reduction, product differentiation, innovation capability, logistical efficiency, or whatever. Thus Nike has been seen as exemplifying a 'buyer-driven' supply chain, where the design and marketing node of the supply chain and its associated brand marque form the dominant power. This in turn affects the nature of the competition and its locus and focus in relation to other competitors, such as Reebok and Adidas (Gereffi and Korzenewiecz, 1994). But power can equally be situated upstream, as in the case of Monsanto and the biotechnology of seed manufacturing, 'mid-stream' as in the case of motor-manufacturers, or downstream, as in the case of UK food supermarkets or many clothing retailers. Thus, in as much as supply chains, or other less linear inter-firm entities, produce outputs for given product markets, they can become in Polanyan terms relatively normal and stabilised forms of industrial organisation, reflecting also a normalisation over periods of time of power asymmetries within them in the markets in which they operate. There is a consequent channelling of competition and also a focus of competition on different product aspects (novelty, style, marque, quality, freshness, convenience, price, reliability, etc.). Equally, such inter-firm organisations create a halo of competition, again at certain loci of the supply chain, between insiders and outsiders.

\section{Scales of competition}

From an IEP perspective different scales of markets can be seen to be the results of historical processes of institution, ${ }^{16}$ rather than any pre-given frameworks, and as a consequence are intimately connected with the development of the sizes of firms, the lengths of supply chains, as well as with national and supranational organisations such as NAFTA or the European Union. Moreover, different scales overlay each other, rather than necessarily replacing each other, so that competition, as it were, plays in different registers at the same time. When Krugman (1994, p. 44) argues that 'competitiveness is a meaningless word when applied to national economies' he is in effect arguing that the kind of competition which occurs between firms does not occur between nations or at different scales. That seems to be self-evident. It does appear to be meaningless if a nation is treated as a mega-firm producing a bundle of commodities traded in a multitude of markets at all different scales competing with other such mega-firms. But in so far as nations, in their capacity to set incentives for foreign direct investment or regulatory environments for trading, or infrastructural support for education, or any number of other 
distinctive and formative institutional measures, ${ }^{17}$ can affect the ensemble of nationally active economic agents, it is clear that there is a form of competition distinctive to nations as a class of economic agent. Similarly the formation of supranational scales, such as NAFTA or the EU involve distinctive competitive regulatory frameworks which can accentuate market integration over other competitive criteria such as market share, inter-firm vertical constraint, or cartelisation (Anderman, 1997; Deakin, Goodwin and Hughes, 1997). So the institution of different overlaying scales of markets is a historical process which generates new forms of competition at different registers. To continue the musical metaphor, there is no presumption of harmony between scales, and the emergence of new scales can be discordant in relation to 'normal' forms of competition at other scales.

\section{Norms and formal institutions of competition}

The arguments of Best (1990) and Deakin, Goodwin and Hughes (1997) that formal normative institutions regulating competition evolve in relation to organisations of units of competition as they in turn evolve, ${ }^{18}$ suggest a complex interaction between formal frameworks and informal norms of competitive process. Regulation can thus stimulate vertical integration at the expense of inter-firm co-operation, but in circumstances where stockmarkets as a main feature of capital markets can also lead to more predatory merger and acquisition processes than in economies where long-term banking finance plays a greater role. Particular firm-market structures can become normalised over quite long periods, and thereby establish norms of competition. During processes of restructuration of industrial organisation, or, for example, shifts in the location of power along supply chains, these norms become destabilised, and as the market is re-formed 'abnormal' or market destabilising turbulence occurs. Examples of how one competitive configuration replaces another are given below, but there is a sense in which such processes of institution involve the supersession of one mode of competition by another, rather than competition between one productive system and another. But, equally, different and conflicting modes of competition can continue to exist side by side: 'New Competition' is far from having driven out 'Old Competition'. In speaking of 'norms' of competition, therefore, and of the co-evolution of formal regulatory and non-formal norms of competition, there is no presumption of a functionalist process of mutual adaptation.

From the above discussion of different dimensions of competition as instituted economic process, it is clear that competition is complex, multidimensional and variable, both historically and comparatively. Changes in the nature of the competitive process in terms of how 'atomistic' or firm-oriented it is co-varies often with changes in the object or focus of the competitive process. Under specific, possibly unusual, empirical conditions, purely narrow price competition for homogenous products and high levels of transparency, under conditions of relative equality, may occur. But to do so, infrastructural conditions, and particular market rules, need to be instituted. There is 
indirect competition between labour markets and product markets, product markets and capital markets, and the relationship between these different markets is open to variable historical processes of institution and reconfiguration. Different forms of competition operate at different scales of competition, so that competition is operating in several registers simultaneously. And, finally, there is a complex interaction between formal norms of competition enshrined in competition regulation and the non-formal norms of competition occurring in relatively stable, often quite long-term, market formations. To illustrate this multi-dimensionality, and the process of de-institution and re-institution of different forms of competition, discussion now turns to the effects of the changes in the UK food retailing market.

\section{UK supermarkets and changing forms of competition ${ }^{19}$}

During the course of the twentieth century, UK multiple retailers have grown from having roughly ten per cent of the market share of the food market to over 85 per cent. In a first phase, multiple retailers established an integrated national market for food retailing (Jefferys, 1954). In a second phase, from the early 1970s, but accelerating through the 1980s, the small handful of major retailers established a commanding share, and two, Tesco and Sainsbury, contested for market leadership (Wrigley and Lowe, 1996). As a mark of their power, these two market the highest supermarket ownlabel proportion of goods of any food retailers - in many product ranges well over 50 per cent and in key ranges up to 100 per cent. This is a story of growth as much as of competition, and competition between these rivals alone would be insufficient to explain the structural changes that have taken place.

In terms of the IEP approach developed above, this rise to power of supermarkets can be seen to have fundamentally altered all dimensions of competition, and the forms of competition, within this sector, by

- instituting new market forms for consumer markets and intermediate markets;

- altering the asymmetrical power relations, changing the structure of mutual dependences and forming new units of competition between supply chains;

- re-channelling competition, giving it a new locus and focus;

- changing the distributed nature of innovation, and also the innovation process and style; and

- provoking a conflict between an 'old-style' regulatory regime relating to earlier forms of competition and the new norms of competition.

The significance of this change arises from the combination of all of these processes, but, for analytical purposes, each will be briefly separately discussed below. 


\section{The institution of new markets}

The new supermarkets fundamentally restructured the end market, by creating the comprehensive one-stop-shop food and household provisions' retailing outlet. The essential characteristic of these retail outlets is that they trade in total ranges of commodities. The competition is between traders in the totality of the ranges and services they have on offer, rather than in specific product to product competition. Consequently, through either out-of-town or town-based superstores, they aggregate demand over distinctive catchment areas, and adapt product ranges to the socio-economic characteristics of those areas. They also effectively eliminated wholesale markets as intermediary markets, and thus eradicated the forms of competition typical of those markets by bypassing them. The typical instituted form of those wholesale markets was to operate as spot markets, with very short-term, price-focused and market-clearing competition. The structure of trading had been for a large plurality of primary producers to supply a relatively small number of wholesalers who traded with a large plurality of retailers on a commission basis. From the mid-1980s, supermarkets centralised their purchasing activities, bought direct from primary producers, with whom they established relatively long-term, often exclusive, trading relations.

\section{New asymmetric power relations of mutual dependence, new units of competition}

The concentration of power in the hands of two or three major multiples has resulted in a radical shift in power in relation to at least three other classes of economic agent: consumers, primary producers, and food manufacturers and processors. In relation to consumers, the operation of catchment areas, in which one major store is locationally strongly advantaged in respect of a large number of consumers can create a quasi-monopoly position. Reinforced through various 'loyalty card' electronic point of sale (Eftpos) schemes, the result is that 70 per cent of the majority of shoppers' grocery purchases is undertaken regularly in one store.

In relation to brand manufacturers, major international companies, with global presence, are constrained to produce own-label products under supermarket specification. In short, where competition does occur between ownlabel and branded goods, retailers are in a powerful position to set the terms of that competition.

But perhaps it is in relation to own-label producers that the most conspicuous changes have taken place. As a consequence of the development of own-label manufacture, five or six major own-label manufacturers supply the bulk of all own label produce to a similar number of retail multiples, creating a complex interlocking matrix of exclusive trade in relation to particular products and product ranges. Typically, one of the large own-label manufacturers will have a number of factory units, each dedicated to the exclusive supply to one of the major multiples. For example, one company provides all the lasagne, each under a different specification and design, to the top five retailers. Or, for pizzas, two manufacturers supply one retailer with different 
segments of the pizza market, also on an exclusive basis. This type of 'multiple and criss-crossing monopsony' between relatively low numbers of trading partners on either side of the exchange, means that competition is reduced significantly between own-label manufacturers, and orchestrated at the retail-consumer end through the retailers' integration of the ranges of products that they obtain from manufacturers. Moreover, retailers audit and specify the suppliers used by the own-label manufacturers and, in cases of long-term relations, operate on the basis of 'open accounts'. This 'monopsonistic matrix' is not easily described in terms of vertical constraint or quasivertical integration, in as much as they any given own-label manufacturer has a number of exclusive relations with retailers, and vice versa.

In relation to primary producers of fresh produce, direct purchase has led to a massive concentration of the supply base, and long-term, often exclusive, trading relationships between retailers and primary producers. The effect of this is to relocate competition from a process occurring between large numbers of primary producers, to competition within a periphery of contingent suppliers striving to become established in the core of long-term stable suppliers. The competition thus changes in nature, from a focus essentially on price to a focus on the capacity to produce consistently to the specification of supermarkets, across a differentiated product range and quality, over the long term.

Overall the effect of this shift in asymmetrical power is to create new forms of mutual dependence, of locked-in long-term trading relationships. It is clear that this is not a form of co-operation between similar economic agents under conditions of complementarity, but a form of co-ordination, often involving high levels of trust and also of mutual recognition of where the power lies. As a result, new units of competition have been developed which have displaced the old. In terms of definition of the market, there is a sense in which the residual independent small retailers are not being eliminated through competition with supermarkets (Competition Commission, 2000), strictu sensu, but are being superseded by a different form of retail organisation, with competition now occurring between superstore companies each with its particular supply chain, logistical system and productive innovation capabilities.

\section{The re-channelling of competition}

As a result of the formation of new market organisation and new units of competition, it can be seen that competition is squeezed to the ends and the peripheries of the supply chains, on the one hand, and between rival supermarket chains at a national scale, on the other. Within the supply chains, competition is replaced by the power to transmit and displace competitive pressures downwards from the 'front end'. So, within the units there is not so much direct competition between equivalent economic agents (own-label manufacturers, primary core exclusive suppliers), as an exercise in relative power to displace competitive pressure from the front end, subject to the constraints of maintaining trust and partnership. 


\section{New forms of innovation and distributed innovation process}

The development of these new units of competition has involved, pari passu, the development of both new forms of organisation and innovation process, distributed across different agents within, and intersecting with, the supply chain. A striking example of such a process might be the way in which a major supermarket orchestrated the development and introduction of biological pest controls in southern Spain with a biotechnology company, which produced the beneficial pests, the tomato growers, and the training and technical support bodies in the region. It is obvious that such an innovation process requiring co-ordination between a number of diverse agents by a retailer involves a quite different form of trading relationship between those agents than in earlier retailing epochs. An equally striking example is the way in which retailers combine with an exclusive own-label manufacturer, TV chefs, and chic metropolitan restaurants, to deliver a constant stream of fashionfollowing-and-setting products onto the supermarket shelf. The own-label exclusive trading relationship, by giving secure market access to the manufacturers, and rapid lines of communication, reduces the time from concept to market from about two years to as little as four weeks. Consequently, compared to the typical innovation style of a major branded manufacturer normally launching four or five new products per year, who has to secure market access and presence through advertising and many other sunken costs, the own-label manufacturer normally launches over 1,000 products, many of them with a short lifecycle. In this latter style of innovation, the new products are effectively creating a new consumer food market, of different demand characteristics, rather than simply copying and undercutting branded products within the same market segment.

Conflict between formal and non-formal norms of competition

In 1999 the Office of Fair Trading referred the grocery retailing sector to the Competition Commission, to determine whether a monopoly existed within the sector, whether a monopoly situation was being exploited, and whether the monopoly, if it existed, operated against the public interest. The terms and formal norms of the competition inquiry were based on assumptions about the nature of competition which belong to a different structure of markets and organisation of economic agents, still largely concerned with price competition, measured by 'the shopping basket' (Office of Fair Trading, 1997). Thus, the problem was identified in terms of whether competition existed 'in catchment areas where consumers have little choice of supermarkets' and that their 'power may become exploitative' in relation to their suppliers (in reference to the Competition Commission, November 1999). Yet, on the one hand, superstores require catchment areas, which, if not exclusive, provide a secure breadth and depth of aggregate demand. Clusters of small independent retailers offering similar products in close proximity in a given highstreet reflects a particular organisation of the retail market, and a similar geographical arrangement for superstores would be unsustainable. 
On the other, supply chains dominated and orchestrated by retailers, with long-term insiders and contingent outsiders, comprise the basis on which supermarkets have developed the distributed capacity to deliver an entirely new product range and style of product innovation. We have seen how the perhaps bizarre matrix of trade between own-label manufacturers and large retail multiples defies normal categories of cartelisation, vertical constraint or integration. Thus, we are witnessing a conflict between new instituted non-formal norms of competition and existing, 'anachronistic' formal norms of competition (Competition Commission, 2000). That is not to say, of course, that the outcome of the conflict is one in which the 'new' will prevail over the 'anachronistic', especially if the latter facilitates the entry into the market of a new discount-oriented, price-focused, retail model following Wal-Mart's acquisition of Asda.

\section{Conclusion}

The rise in the relative power of UK supermarkets has been given as an example of how the restructuration of a sector has resulted in new forms of competition as an instituted economic process. This analysis of forms of competition in terms of a number of interrelated dimensions has focused on the processes of the institution of competition, rather than classifying or defining types of competition. The interest of the case of UK supermarkets is not so much that it represents the result of a particular historical institution of competition (which may or may not last, spread or contract), as that it reveals processes of transformation from one form of competition to another, and the dynamics of that transformation. Perhaps the most significant aspect of this analysis is that a particular norm of instituted competitive process is the outcome of this multi-dimensional restructuration, rather than the outcome of competition itself. A process of competition is the historical result of the transformations of markets, the formation of new units of competition and of new scales of markets, the re-shaping and creating of new classes of economic agent with new asymmetries of power and mutual dependence, and an interaction between formal and non-formal norms of competition, rather than an independent, sui generis, dynamic force. With varieties of capitalism go varieties of competition, and explanations must look to dynamics and processes of variation.

\section{Notes}

1 'Ultimately, rivalry must evolve beyond cost to include differentiation' (Porter, 1998a, p. 213).

2 'Viewing a group of companies and institutions as a cluster highlights opportunities for co-ordination and mutual improvement in areas of common concern without threatening or distorting competition or limiting the intensity of rivalry' (Porter, 1998a, p. 205).

3 This view has been further developed in an analysis of the historical comparative 
advantage held by regionally developed capabilities, and new modes of productive organisation exemplified by Boston's Route 128 (Best, 2001). See also chapter 9, this volume.

4 The focus is also on vertical constraint in supply chains, the subject of further discussion below.

5 To take another classical sociologist, Simmel, it is possible to envisage forms of competition which, far from acting to the detriment of others, simply spur others to produce greater variety (Swedberg 1994, p. 272). That conception is one which almost presupposes growth, an expanding market, which does not reside in efficient allocation of existing resources, with some losers and some gainers. In ways which seem to foreshadow Porter's 'positive sum' world of potential winners, this 'benign' and 'emulatory' competition in exchange relies on productive capacities for growth lying outside exchange.

6 'The human economy, then, is embedded and enmeshed in institutions economic and non-economic' (Polanyi, 1957, p. 250). Note here the ambiguity of human economy being embedded in economic institutions.

7 'The electric utility industry was born not out of Benthamite Equations or optimising rationality, but longstanding friendships, similar experiences, common dependencies, corporate interlocks, and active creation of new social relations. Samuel Insull and his circle of collaborators socially constructed their firms in similar ways, and then promoted a system of industry governance and template diffusion. They drew upon their local and national contacts to re-frame the market and the political system in ways that pressured utility firms toward technical, organisational, economic and legal conformity' (Granovetter and McGuire, 1998, p. 167).

8 'The actor's ontology is variable: his or her objectives, interests, will and thus identity are caught up in a process of continual reconfiguration, a process that is intimately related to the constant reconfiguration of the network of interactions in which he or she is involved' (Callon, 1998, pp. 252-3).

9 "In this "hot" world, which is becoming increasingly difficult to cool down, the work of economists is becoming ever more arduous because the actors they are tracking are faced by non-calculable decisions' (Callon, 1998, p. 263). He argues that societies are increasingly 'hot' in this sense, because of the role of rapid innovation, and in a quite technoscientific deterministic fashion suggests that what makes societies 'hot' is that 'technosciences ... cause entanglements and networks of interdependencies to proliferate at their leisure - the market must be constantly reformed and built up from scratch' (ibid., p. 266).

10 'The anonymous market of neo-classical models is virtually non-existent . . Transactions of all kinds are rife with social connections ...' (Granovetter, 1985, p. 495).

11 As suggested in a preliminary way by Swedberg (1994, pp. 273-4)

12 Most notably analysed by Marx, Capital, Vol. 1.

13 This is not to say, of course, that capital and labour factor inputs cannot be substituted for one another on occasions, depending on the relative costs of such factor inputs.

14 Best characterises the Marshallian district as one of static complementarities, as against New Competition dynamic complementarities arising from continual mutual enhancement of dissimilar but complementary capabilities (1990, p. 235).

15 To stress the multi-dimensional aspect of such competition, there can be different scales of product, labour, and capital market competition at play simultaneously. 
16 Braudel's 1982 work exemplifies a long duration approach to the historical formation of different scales of market formation.

17 For example the International Institute of Management Development's World Competitiveness Yearbook (2000) uses a battery of different measures to rank nations in terms of how nations provide 'firms with an environment that sustains the domestic and global competitiveness of the firms operating in their borders'.

18 And indeed as a response to shifts in dominant economic orthodoxies.

19 This illustrative example is based on research undertaken between 1997 and 2000 which used the tomato as an empirical probe to explore the relationships occurring in supply chains and markets, and the way these shaped innovation processes. Interviews were conducted along the length of the chain, and in the networks surrounding different nodes of the chain. Seed manufacturers, biotechnology companies, scientists, own label and brand manufacturers, supermarkets, wholesale markets, logistics companies, importers, and a number of other key players were interviewed during the course of this research.

\section{References}

Anderman, S. (1997), 'Commercial co-operation, international competitiveness and EC competition policy', in Deakin, S. and Michie, J. (eds), Contracts, Co-operation and Competition. Studies in Economics, Management and Law, Oxford, Oxford University Press.

Arighetti, A., Bachmann, R. and Deakin, S. (1997), 'Contract law, social norms and inter-firm co-operation', The Cambridge Journal of Economics, 21(2), pp. 171-96.

Best, M. H. (1990), The New Competition. Institutions of Industrial Restructuring. Cambridge, MA, Harvard University Press.

Best, M. H. (2001), The New Competitive Advantage. The Renewal of American Industry, Oxford Oxford University Press.

Braudel, F. (1982), The Wheels of Commerce. Civilisation and Capitalism, London, Fontana, Vol. 2.

Callon, M. (1998), 'An essay on framing and overflowing: economic externalities revisited by sociology', in Callon, M. (ed.), The Laws of the Markets, Oxford, Blackwell, pp. 244-69.

Competition Commission (2000), Supermarkets. A Report on the Supply of Groceries from Multiple Stores in the United Kingdom, London, HMSO.

Deakin, S., Goodwin, T. and Hughes, A. (1997), 'Co-operation and trust in inter-firm relations: beyond competition policy?', in Deakin, S. and Michie, J. (eds), Contracts, Co-operation and Competition. Studies in Economics, Management and Law, Oxford, Oxford University Press.

Deakin, S., Lane, C. and Wilkinson, F, (1997), 'Contract law, trust relations, and incentives for co-operation: a comparative study', in Deakin, S. and Michie, J. (eds) Contracts, Co-operation and Competition. Studies in Economics, Management and Law, Oxford, Oxford University Press.

Deakin, S. and Michie, J. (eds) (1997), Contracts, Co-operation and Competition. Studies in Economics, Management and Law, Oxford, Oxford University Press.

Deakin, S. and Wilkinson, F. (1995), Contracts, Co-operation and Trust: The Role of the Institutional Framework, Working Paper No. 10, ESRC Centre for Business Research, University of Cambridge. 
Dei Ottati, G. (1994), 'Co-operation and competition in the industrial district as an organisation model', European Planning Studies, 2, pp. 463-83.

Fulconis, F. (1999), 'Les "structures en réseau": nouvelle forme de concurrence', in Krafft, J. (ed.), Le Processus de Concurrence, Paris, Economica, pp. 202-19

Garcia, M.-F. (1986), 'La construction sociale d'un marché parfait: le marché au cadran de Fontaines-en-Sologne', Actes de Recherche, 65, pp. 2-13.

Gereffi, G. and Korzenewecz, M. (1994), Commodity Chains and Global Capitalism, Westport, CT, Praeger.

Granovetter, M. (1985), 'Economic action and social structure: the problem of embeddedness', The American Journal of Sociology, 91(3), pp. 481-510.

Granovetter, M. (1992), 'The sociological and economic approaches to labour market analysis: a social structural view', in Granovetter, M. and Swedberg, R. (eds), The Sociology of Economic Life, San Francisco, Westview Press.

Granovetter, M. and McGuire, P. (1998), 'The making of an industry: electricity in the United States', in Callon, M. (ed.), The Laws of the Markets, Oxford, Blackwell, pp. 147-73.

Harvey, M. (2000), 'Systemic competition between high and low "social cost” labour: a case study of the UK construction industry', in Clarke, L., de Gijsel, P. and Janssen, J. (eds), The Dynamics of Wage Relations in the New Europe, Boston, MA, Kluwer Academic Publishers.

Harvey, M., Beynon, H. and Quilley, S. (forthcoming), 'Processes of variation: how capitalism appropriated the tomato', in Harvey, M. and Beynon, H. (eds), Capitalism or Capitalisms? Approaches to Varieties of Capitalism, Manchester University Press.

International Institute for Management Development (2000), World Competitiveness Yearbook, available online: www.02.ind.ch/wcy.

Jefferys, J. B. (1954), Retailing Trading in Britain 1850-1950, Cambridge, Cambridge University Press.

Krugman, P. (1994), 'Competitiveness: a dangerous obsession', Foreign Affairs, 73(2), pp. 28-44.

Lane, C. (1997), 'The social regulation of inter-firm relations in Britain and Germany: market rules, legal norms and technical standards', The Cambridge Journal of Economics, 21(2), pp. 197-217.

Office of Fair Trading (1997), Competition in Retailing, prepared by London Economics, Research Paper 13, London, HMSO.

Polanyi, K. (1944), The Great Transformation. The Political and Economic Origins of Our Time, Boston, MA, Beacon.

Polanyi, K. (1957), 'The economy as instituted process', in Polanyi, K., Arensberg, C. M. and Pearson, H. W. (eds), Trade and Market in the Early Empires, New York, Free Press, pp. 243-70.

Porter, M. E. (1985), Competitive Advantage: Creating and Sustaining Superior Performance, New York, Free Press.

Porter, M. E. (1998a), 'Clusters and competition', in On Competition, Boston, MA, Harvard Business Review, pp. 197-288.

Porter, M. E. (1998b), 'Competing across locations', in On Competition, Boston, MA,, Harvard Business Review, pp. 309-47.

Richardson, G. B. (1972), 'The organisation of industry', Economic Journal, 82, pp. 883-96.

Swedberg, R. (1994), 'Markets as social structures', in Smelser, N. and Swedberg, R. 
(eds), The Handbook of Economic Sociology, New Jersey, Princeton University Press, pp. 255-82.

Swedberg, R. (1998), Max Weber and the Idea of Economic Sociology, New Jersey, Princeton University Press.

Swedberg, R. (forthcoming), 'Max Weber's sociology of capitalisms', in Harvey, M. and Beynon, H. (eds), Capitalism or Capitalisms? Approaches to Varieties of Capitalism, Manchester University Press.

Weber, M. (1968 [1922]), Economy and Society. An Outline of Interpretive Sociology, ed. Roth, G. and Wittich, C., New York, Bedminster Press.

Wrigley, N. and Lowe, M. (eds) (1996), Retailing, Consumption and Capital. Towards the New Retail Geography, Harlow, Longman. 